ORIGINAL ARTICLE

\title{
Changing socioeconomic inequality in infant mortality in Cumbria
}

\section{T J B Dummer, L Parker}

See end of article for authors' affiliations

....................

Correspondence to: Prof. L Parker, Paediatric and Lifecourse

Epidemiology Research Group, Sir James Spence Institute of Child Health, Newcastle University, Royal Victoria Infirmary, Queen Victoria Road, Newcastle NE1 4LP, UK; lovise.parler@ncl.ac.uk

Accepted 11 July 2004

\begin{abstract}
Aims: To investigate infant deaths in Cumbria, 1950-93, in relation to individual and community level socioeconomic status.

Methods: Retrospective birth cohort study of all 283668 live births and 4889 infant deaths in Cumbria, 1950-93. Community deprivation (Townsend score) and individual social class were used to estimate socioeconomic status. Logistic regression was used to investigate risk of infant death (early neonatal, neonatal, and postneonatal) in relation to social class and Townsend deprivation score, adjusting for year of birth, birth order, multiple births, and stratified by time period, 1950-65, 1966-75, 1976-85, 1986-93.

Results: The risk of infant death in all categories was higher in the lower social classes and more deprived communities, although inequality in risk of neonatal death declined after 1975 to such an extent that there was no significant difference in neonatal death rates by socioeconomic status in the most recent time period. By contrast, there was no narrowing in socioeconomic inequality in postneonatal death risk over the study period. Community deprivation was associated with a significant increased risk of postneonatal death after adjusting for individual level socioeconomic status.

Conclusions: Postneonatal deaths remain higher in the most deprived communities and in the more disadvantaged social classes. The social, lifestyle, and environmental determinates of adverse health outcomes for children need to be fully understood, and interventions should be designed and targeted at the more socially deprived sectors of our community.
\end{abstract}

D espite a comprehensive health and welfare system, mortality and morbidity in the UK is higher in deprived communities and in those from the lower social classes. ${ }^{1-3}$ In general, improvements in the health of adults have been greatest for the most affluent, with comparatively little-and delayed-improvement in the health of the most deprived. ${ }^{245}$ Thus, in the UK, there is substantial evidence of widening inequalities in adult health, ${ }^{3}$ a problem compounded by persistent inequalities in socioeconomic status and living conditions. ${ }^{15}$ With respect to children, over the past 50 years there has been a huge fall in infant mortality in the UK, highlighting a general trend of improving child health. ${ }^{6}$ However, despite such improvements, infant mortality remains higher in more deprived social groups and is higher than in other comparably affluent countries. ${ }^{2} 7$

While there is substantial evidence of increasing socioeconomic inequalities in mortality and morbidity in the $\mathrm{UK}^{2}{ }^{258}$ the specific role of income in mediating socioeconomic inequalities in health is less clear. ${ }^{9}{ }^{10}$ In particular, there is debate over whether relative income inequality at the community or individual level is the major driver of socioeconomic variations in health. ${ }^{10}{ }^{11}$ Socioeconomic status, such as social class, is a surrogate indicator of a complex social phenomenon, which includes individual income, psychosocial stress, and material conditions. ${ }^{12}$

In a previous study we showed that socioeconomic inequality in stillbirth risk in Cumbria narrowed significantly after 1975, although rates remained higher in more deprived communities and among those from more disadvantaged social classes. ${ }^{13}$ This study investigated socioeconomic inequality in risk of infant death in Cumbria, 1950-93, in order to determine whether infant deaths in Cumbria showed similar trends to stillbirth rates. Community deprivation (Townsend score) and individual social class were used to delineate socioeconomic status. The relative interplay between individual and community level disadvantage was explored to identify whether the contextual setting of place of birth exerted influence over and above individual socioeconomic status.

\section{METHODS}

\section{Setting and data}

Cumbria is a rural county in northwest England with a population of just under half a million. It has a rich history of mining and heavy industry, although this peaked in the 19th century and many mines had closed by 1950. Only remnants of industries still exist, including limestone quarrying, steelworks, chemical production, and engineering. The nuclear installation at Sellafield, west Cumbria, has operated since 1947 and is a major site for nuclear waste reprocessing. Although there are few settlements above 20000 residents, the presence of the Lake District National Park means the area is a popular tourist destination, attracting many visitors and seasonal workers.

The study cohort consisted of all live and still births in Cumbria, 1950-93, derived from the Cumbrian Birth Database. ${ }^{14}$ For each birth, year of birth, social class, and postcode at birth were recorded from the birth certificate; birth order and multiple birth indicators were derived. All deaths in the cohort were coded to ICD-9 and grouped into categories based on age at death: early neonatal (0-6 days old), neonatal (0-27 days old), and postneonatal ( 28 days to 1 year old). The grid reference at birth was derived from the postcode of the mother's residence at birth.

Townsend deprivation scores ${ }^{15}$ were calculated from 1971, 1981, and 1991 enumeration district (ED) level census data. The 1991 census deprivation scores were linked to individual births using the grid reference at birth and boundaries of EDs. Because no digitised ED boundary data were available for the 1971 and 1981 censuses, deprivation scores were 
interpolated between ED centroids using the geographical information systems (GIS) Arc/Info ${ }^{16}$ and then assigned to individual births. ${ }^{13}$

\section{Data analysis}

To allow for the large reduction in infant deaths over the study period, and because the Townsend scores were derived from different censuses and not strictly comparable, the data were stratified by time period (1950-65, 1966-75, 1976-85, 1986-93). Within each time period infant death rates were calculated for all social classes (I, II, IIIn, IIIm, IV, V; father not recorded on the birth certificate; armed forces and unknown). The population was ranked by the deprivation score of the ED at birth, grouped into quintiles of approximately equal numbers of births, and the rate for each quintile was calculated.

Inequality in infant death risk between socioeconomic strata (social classes $\mathrm{I}-\mathrm{V}$ or deprivation score) in each time period was measured using the relative index of inequality (RII). ${ }^{17}$ The RII measures the trend in risk across the social strata, allowing for the number of births in each group, hence comparisons of risk in different time periods are not distorted by changes in the numbers of births in each group. An RII of 2 indicates a doubling of risk between the top and the bottom of the social hierarchy. Logistic regression was used to estimate the RII, after adjusting for year of birth, birth order, and multiple births. Because multiple births were included in the analysis, robust estimates of variance were used. ${ }^{18}$ The OR for the risk of infant death among children whose father was unrecorded (lone or unsupported mothers) compared to all others was also estimated using logistic regression, adjusting for covariates as before. Analysis was carried out using the statistical package STATA. ${ }^{19}$

To investigate the change in the effect of deprivation over time, analysis was undertaken for the time period 1966-93, with the 1981 and 1991 deprivation score variables standardised to the 1971 census, ${ }^{20}$ allowing comparison of deprivation relative to 1971. The change in inequality (social class and deprivation) since 1966 was assessed from the interaction between RII and year of birth.

The effect of community level disadvantage (deprivation score), after adjusting for individual level disadvantage (social class), and vice versa, was assessed using logistic regression-adjusting for covariates as before.

The goodness of fit of the final logistic regression models was assessed by the Hosmer and Lemeshow deciles of risk statistic, $^{21}$ which compares the observed and expected numbers of cases in 10 groups containing equal numbers of births.

\section{RESULTS}

\section{Unadjusted infant mortality rates (tables 1-3)}

Consistent with national data, ${ }^{6}$ early neonatal and neonatal death rates were markedly higher than postneonatal death rates. Rates for each outcome fell dramatically over time in all social classes and for all levels of deprivation.

There was an increasing rate of early neonatal, neonatal, and postneonatal death with decreasing social class in the two earlier time periods, but little evidence of a social class effect after 1975 for early neonatal deaths, or after 1986 for neonatal deaths. The rates for babies where the father was unrecorded were generally at least 1.5 times as high as in any other group, though this effect was less marked in the most recent time period.

In the earlier time period (1966-75) infant death rates increased with higher levels of community deprivation. However, in 1986-93 early neonatal and neonatal death rates in each quintile of deprivation were very similar. In contrast, the postneonatal death rate was around twice that

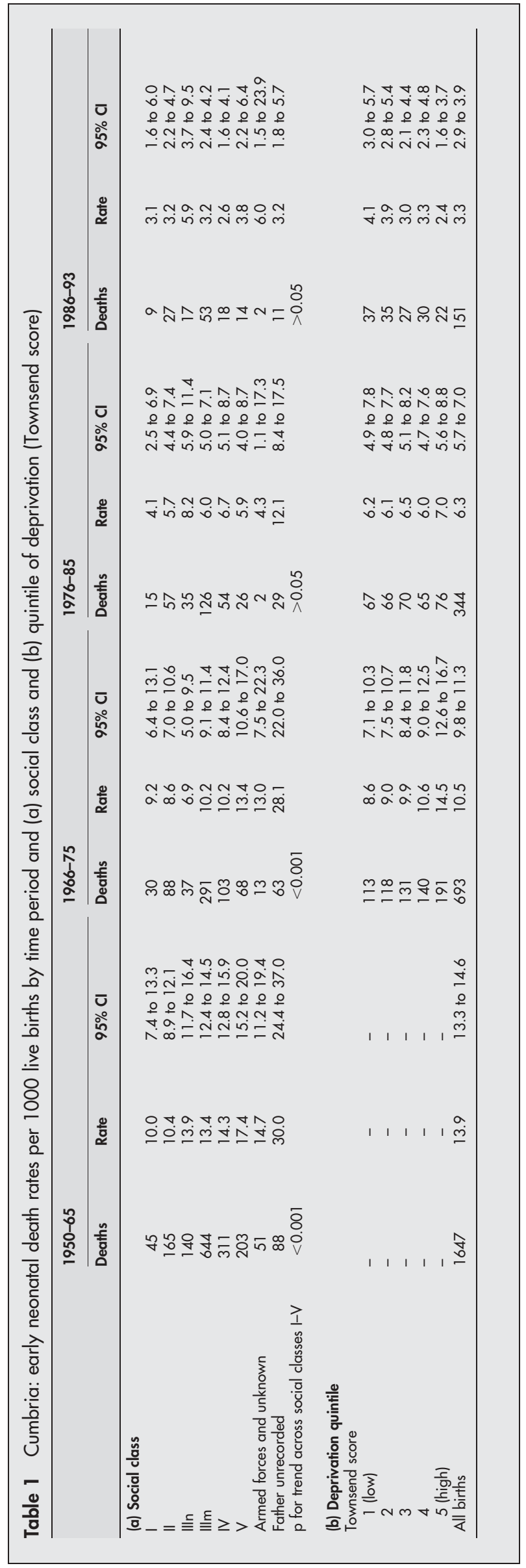



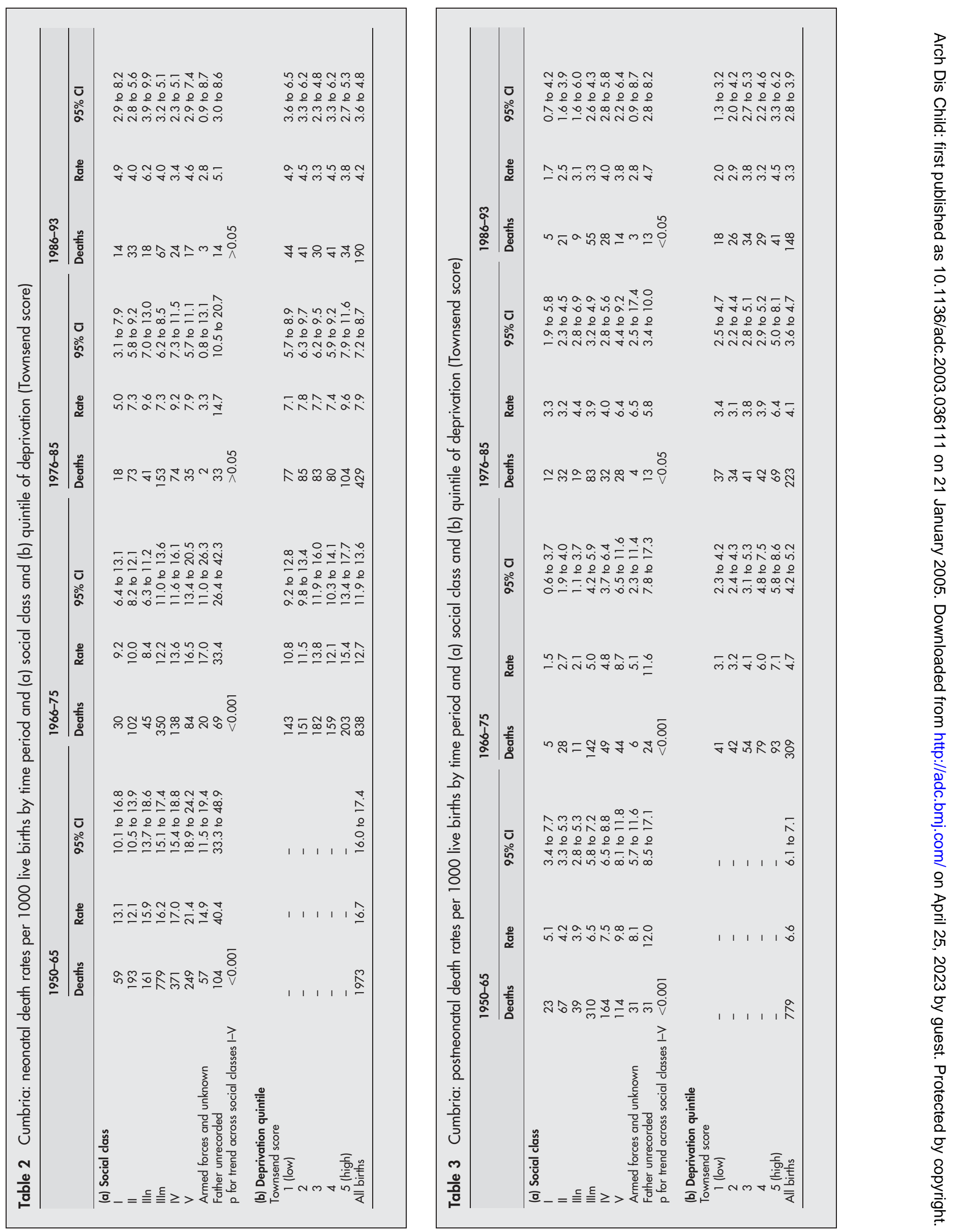
in the highest quintile compared to the lowest quintile of deprivation in all time periods.

Socioeconomic inequality in infant death risk (table 4) The risk of early neonatal and neonatal death was significantly higher for births in the less advantaged social classes in the earlier time periods (1950-75) but not subsequently. There was a significant narrowing of inequality in risk of neonatal death between social classes I-V from 1976 onwards $(\mathrm{p}<0.05)$. In contrast, there was a significantly increased risk of postneonatal deaths in the more disadvantaged social classes in all time periods-except for 1976-85 which was borderline significant $(p=0.06)$. Inequality in risk of postneonatal mortality across the social classes did not narrow significantly over time $(\mathrm{p}=0.13)$.

An increased risk of early neonatal, neonatal, and postneonatal death was evident for babies where the father was unrecorded in all time periods except 1986-93. Since 1966 there was significant narrowing of inequality in risk of infant death for babies where the father was unrecorded compared to all other social classes $(p<0.05)$.

There was significant inequality in early neonatal, neonatal, and postneonatal death risk between mothers living in areas with different levels of deprivation in 1966-75. However, during 1986-93 significant inequality in risk remained only for postneonatal deaths-the RII indicating more than a doubling of risk of postneonatal death for babies born to mothers living in the most deprived areas compared to the least deprived areas, which was similar in all time periods. The association between inequality (community deprivation) and risk of early neonatal and neonatal death risk attenuated significantly after $1976(\mathrm{p}<0.05)$.

In all time periods community deprivation independently accounted for significant variation in postneonatal death rates, even after the effects of individual social class were adjusted for $(1966-75, \mathrm{p}<0.001 ; 1976-83, \mathrm{p}=0.01$; 198693, $\mathrm{p}<0.05)$. However, social class only accounted for significant variation in postneonatal deaths after adjustment for deprivation in 1966-75 ( $\mathrm{p}<0.001$ ). By contrast, neither early neonatal nor neonatal deaths displayed significant variation with deprivation after adjustment for social class ( $p>0.05$ in all time periods). Social class accounted for significant variation in early neonatal and neonatal deaths after adjustment for deprivation in all time periods $(p<0.01)$, except for neonatal deaths in 1986-93 $(p>0.05)$ when no effect with social class was found (table 4). There was some confounding between community deprivation and individual social class. The Hosmer and Lemeshow deciles of risk statistic confirmed the goodness of fit of each model in each time period $(\mathrm{p}>0.1)$.

\section{DISCUSSION}

\section{Summary of results}

Between 1950 and 1965 there was a highly significant increased risk of infant death (early neonatal, neonatal, and postneonatal deaths) in those from less advantaged social classes. In the subsequent time period, 1966-75, community deprivation (Townsend score) and individual social class were independently associated with infant death risk in all three categories. However, the RII showed that inequality in risk (social class and community deprivation) for early neonatal and neonatal deaths narrowed significantly between 1966 and 1993. By contrast, inequality in risk for postneonatal deaths (social class and material deprivation) did not attenuate significantly during the study.

Births where the father was unrecorded on the birth certificate (unsupported mothers) were at exceptionally high risk of infant death throughout the study period, except for the most recent time period, when the proportion of births in this group had more than doubled, and the characteristics of the women in this group were likely to have changed. ${ }^{13}$ This high risk probably reflects not only extreme economic disadvantage, but also more teenage pregnancies, a lower level of education, and a higher prevalence of smoking among this group of women. ${ }^{22} 23$

Table 4 Cumbria: relative index of inequality (RII), for early neonatal, neonatal, postneonatal deaths in relation to social class and community deprivation, and odds ratio (OR) for infant deaths among babies with father unrecorded, compared to all others

\begin{tabular}{|c|c|c|c|c|c|c|c|c|}
\hline \multirow[b]{3}{*}{ Death time period } & \multirow[b]{3}{*}{ Livebirths } & \multirow[b]{3}{*}{ Cases } & \multicolumn{4}{|c|}{ Individual level indicator } & \multirow{2}{*}{\multicolumn{2}{|c|}{$\begin{array}{l}\text { Community deprivation } \\
\text { (Townsend score) }\end{array}$}} \\
\hline & & & \multicolumn{2}{|c|}{$\begin{array}{l}\text { "Father unrecorded" compared } \\
\text { to all others }\end{array}$} & \multicolumn{2}{|l|}{ Social classes I-V only } & & \\
\hline & & & OR $(95 \% \mathrm{Cl})$ & $p$ & RII $(95 \% \mathrm{Cl})$ & p & RII $(95 \% \mathrm{Cl})$ & p \\
\hline \multicolumn{9}{|l|}{ Early neonatal } \\
\hline $1950-65$ & 118360 & 1647 & 2.59 (2.06 to 3.32 ) & $<0.001$ & 1.52 (1.27 to 1.84$)$ & $<0.001$ & - & - \\
\hline 1966-75 & 65903 & 693 & 2.71 (2.06 to 3.58 ) & $<0.001$ & 1.56 (1.16 to 2.09 ) & $<0.001$ & $1.52(1.28$ to 1.81$)$ & $<0.001$ \\
\hline $1976-85$ & 54239 & 344 & 2.03 (1.37 to 3.05$)$ & $<0.001$ & $1.22(0.82$ to 1.81$)$ & 0.34 & 1.19 (0.82 to 1.72$)$ & 0.37 \\
\hline 1986-93 & 45166 & 151 & $1.21(0.65$ to 2.25$)$ & 0.55 & $0.83(0.46$ to 1.50$)$ & 0.54 & 0.59 (0.33 to 1.04$)$ & 0.07 \\
\hline $\begin{array}{l}\text { Change in risk since } \\
1966\end{array}$ & 165308 & 1188 & & $<0.01$ & & 0.16 & & $<0.05$ \\
\hline \multicolumn{9}{|l|}{ Neonatal } \\
\hline $1950-65$ & 118360 & 1973 & 2.64 (2.15 to 3.24$)$ & $<0.001$ & 1.56 (1.31 to 1.85$)$ & $<0.001$ & - & - \\
\hline 1966-75 & 65903 & 838 & 2.66 (2.06 to 3.44$)$ & $<0.001$ & 1.86 (1.42 to 2.43 ) & $<0.001$ & $1.46(1.15$ to 1.85$)$ & $<0.01$ \\
\hline 1976-85 & 54239 & 429 & 1.90 (1.32 to 2.74$)$ & $<0.01$ & 1.36 (0.95 to 1.95$)$ & 0.09 & 1.42 (1.01 to 1.99$)$ & $<0.05$ \\
\hline 1986-93 & 45166 & 190 & 1.19 (0.68 to 2.07$)$ & 0.54 & $0.82(0.50$ to 1.41$)$ & 0.48 & $0.76(0.45$ to 1.27$)$ & 0.28 \\
\hline $\begin{array}{l}\text { Change in risk since } \\
1966\end{array}$ & 165308 & 1457 & & $<0.001$ & & $<0.05$ & & $<0.05$ \\
\hline \multicolumn{9}{|l|}{ Postneonatal } \\
\hline $1950-65$ & 118360 & 779 & 2.25 (1.56 to 3.25$)$ & $<0.001$ & 2.27 (1.73 to 2.97 ) & $<0.001$ & - & - \\
\hline $1966-75$ & 65903 & 309 & 3.13 (2.07 to 4.87 ) & $<0.001$ & 3.44 (2.24 to 5.29 ) & $<0.001$ & 2.92 (1.95 to 4.37$)$ & $<0.001$ \\
\hline $1976-85$ & 54239 & 223 & 1.80 (1.01 to 3.27$)$ & 0.06 & $1.62(0.97$ to 2.70$)$ & 0.06 & 2.25 (1.39 to 3.64$)$ & $<0.001$ \\
\hline 1986-93 & 45166 & 148 & 1.55 (0.87 to 2.76$)$ & 0.16 & 1.90 (1.04 to 3.47$)$ & $<0.05$ & 2.24 (1.25 to 3.98$)$ & $<0.01$ \\
\hline $\begin{array}{l}\text { Change in risk since } \\
1966\end{array}$ & 165308 & 680 & & $<0.05$ & & 0.13 & & 0.62 \\
\hline
\end{tabular}


For all time periods community deprivation independently accounted for significant variation in postneonatal deaths rates, after adjusting for individual level social class, but not vice versa after 1975. Hence, in later time periods the increased risk of postneonatal mortality for more disadvantaged women was mediated through community level deprivation. These results provide evidence of contextual influences on postneonatal mortality over and above the risk related to individual factors associated with social class.

\section{Strengths and weaknesses of the study}

This study covered 44 years, allowing us to investigate changing trends in socioeconomic inequality in infant deaths over a long time period and with a large cohort of over 280000 births. The Cumbrian Births Database recorded all birth registrations in Cumbria during the study period by date of birth and postcode of mother's residence; hence we had precise data on the population at risk and did not have to rely on census estimates. We were able to incorporate individual and community level socioeconomic status within a unified modelling framework, and adjust for a range of demographic risk factors. However, our findings relate to a small area of the UK, which has a distinctive human and physical geography. Hence, while we can infer specific trends for Cumbria from our results, we are cautious in applying these trends nationally.

Our indicator of community level disadvantage was the Townsend score, derived from ED census data. While EDs are the smallest census unit they do not necessarily represent "natural" communities and are not homogeneous in terms of population size. However, EDs are the smallest areal units for which census data are available, and by using GIS we were able to make use of 1971 and 1981 census data despite the unavailability of digital boundary ED data or look-up tables linking postcodes to 1971 and 1981 EDs. We investigated infant death associated with community level disadvantage; however, there was potential for confounding with lifestyle and sociodemographic risk factors that were not included in the analysis, although we were able to adjust for a range of demographic risk factors.

\section{Socioeconomic and temporal trends in child health; comparison with other studies}

Over the course of this study the infant death rate in England and Wales fell from 29.9 per 1000 live births in 1950 to 6.3 per 1000 live births in $1993^{24}$ - similar to the decline from 34.8 to 4.3 deaths per 1000 live births in Cumbria. However, nationally and in Cumbria, neonatal and postneonatal mortality declined at different rates. Neonatal mortality declined considerably after 1950, particularly during the 1970s. ${ }^{25}{ }^{26}$ This decline was due to improvements in health care, the introduction of special care baby units, better maternal diet and nutrition, changing demographic characteristics, and improvements in the survival of low birth weight babies. The slowing down of the decline in neonatal mortality indicates that further reductions through improved medical care may now be limited. ${ }^{26}$ Following a large decline during the 1950s the postneonatal mortality rate has been relatively stable since 1960 in England and Wales, although in 1985 and 1986 an increase was reported ${ }^{26}$ - similar trends were apparent in Cumbria. It has been suggested that in some instances special care baby units delay infant mortality, shifting death into the postneonatal period. ${ }^{24}$ Postneonatal mortality is related primarily to social and environmental conditions, as opposed to medical care. ${ }^{25} 27$ Hence, further improvements in medical care may not tackle the underlying risks that affect postneonatal mortality. Our results of a reduced social gradient in neonatal mortality would be consistent with a reduction in inequality in provision and access to medical care.

Although infant death rates in England and Wales have declined in all social classes, marked differences exist between the least and most disadvantaged groups, with highest rates in the less advantaged social classes..$^{28}$ The social class gradient is steepest within the postneonatal period;:25 29 between 1993 and 1995 the postneonatal mortality rate was more than twice as high in social class $\mathrm{V}$ compared to social class I, whereas for neonatal mortality the rate was 1.5 times higher in social class V compared to social class I. ${ }^{6}$ Evidence also suggests that infant mortality is higher in deprived communities. Morris and colleagues ${ }^{30}$ showed a strong positive link between infant mortality and levels of deprivation and educational attainment in local education authority areas in England. Martuzzi and colleagues ${ }^{31}$ reported perinatal mortality ratios in the North West Thames Health Region increasing from 0.89 to 1.16 between the most affluent and the most deprived wards. While the Cumbrian data were consistent with national trends, there was clear evidence of an attenuation in social class gradient for neonatal deaths, although not for postneonatal deaths.

Infant mortality has been shown to be higher in England and Wales for women solely registering the birth of their baby compared to other women, although the differential in rates declined during the 1990s for perinatal and neonatal mortality, such that there is now little difference in rates between the two groups. ${ }^{24}{ }^{32}$ By contrast, postneonatal mortality remains nearly twice as high for babies registered solely by their mothers compared to babies registered by both parents. ${ }^{32}$ Our findings of no increased risk of infant deaths for unsupported mothers during the final time period contrasts with national trends.

\section{Changing inequalities in infant deaths in Cumbria}

Widening socioeconomic inequalities in health have been reported for adult mortality and mortality among children over 5 years old. ${ }^{156}$ Thus, in general, the overall improvement in the health of society has been brought about by improvements in the health of the most advantaged, with proportionately less improvement, and sometimes decline, in the health of the most disadvantaged. ${ }^{3}$ This contrasts with mortality among infants in the UK, where despite a continuing increased risk in more disadvantaged social classes, inequality between social classes has narrowed. ${ }^{6}$ Hence, our evidence for diminishing inequality in early neonatal and neonatal mortality rates-although only for a small geographical area-is consistent with that reported nationally for infant mortality, and in our previous study of stillbirth rates. ${ }^{13}$

By contrast, persistent socioeconomic inequalities in postneonatal death risk add further weight to the view that postneonatal deaths are influenced by environmental and lifestyle factors ${ }^{27}$ and are less amenable to reduction through medical and health care intervention. We present evidence of an increased risk of postneonatal deaths independently associated with community disadvantage, suggesting that to tackle inequalities in postneonatal mortality social policy and public health needs to be targeted at those most in need. While the focus of such strategies is individuals, our findings indicate that within Cumbria places play a role in creating the context for individual disadvantage and postneonatal mortality. Hence, places need to be considered in policies designed to reduce socioeconomic inequalities in postneonatal deaths.

Our findings extend the debate over the interplay between individual and community risks for adverse health outcomes. ${ }^{4}{ }^{10}{ }^{11}{ }^{33-36}$ This debate concerns identifying whether geographical variations in health occur through contextual 
(community) influences, because places are different, or through compositional (individual) influences, because different sorts of people live in different places. ${ }^{37}$ Thus, the key question concerns whether risk factors relate to features of the environment or features of the individual, and crucially, whether there is an interaction between the community and the individual. Importantly, this study found that postneonatal mortality was independently associated with community deprivation, after controlling for individual socioeconomic status. Hence, the risk of postneonatal death associated with socioeconomic status was mediated through a community (contextual) deprivation effect.

\section{Conclusions}

In Cumbria, evidence of persistent socioeconomic inequalities in postneonatal death risk contrasts with the trends for much narrower inequality for neonatal mortality, and reflects the different aetiology of this component of infant deaths. These results suggest a key area to focus child health improvements: policies need to target the social, lifestyle, and environmental determinates of adverse health outcomes. The complex mechanism through which socioeconomic inequality in risk of postneonatal mortality is mediated requires urgent attention to ensure that the most vulnerable members of our society benefit from the social and medical developments in the 2 lst century.

\section{ACKNOWLEDGEMENTS}

We are grateful to the North of England Children's Cancer Research Fund for ongoing support.

\section{Authors' affiliations}

T J B Dummer, School of Social Science, Liverpool John Moores University, Liverpool, UK

L Parker, Paediatric and Lifecourse Epidemiology Group, School of Clinical Medical Sciences, Sir James Spence Institute of Child Health, University of Newcastle, Royal Victoria Infirmary, Newcastle, UK

Competing interests: none declared

\section{REFERENCES}

1 Townsend P, Davidson N, Whitehead M, eds. Inequalities in health: The Black Report and the health divide. London: Penguin, 1988.

2 DoH (Department of Health). Independent inquiry into inequalities in health (The Acheson Report). London: Stationery Office, 1998.

3 Davey-Smith G, Shaw M, Mitchell R, et al. Inequalities in health continue to grow despite government's pledges. BMJ 2000;320:582.

4 Phillimore P. How do places shape health? Rethinking locality and lifestyle in north-east England. In: Platt S, Thomas H, Scott S, Williams G, eds. Locating health: sociological and historical explorations. Aldershot: Avebury, 1993.

5 Shaw M, Dorling D, Gordon D, et al. The widening gap: health inequalities and policy in Britain. Bristol: Policy Press, 1999.

6 Botting B. Mortality in childhood. In: Drever D, Whitehead M, eds. Health inequalities. London: HMSO, 1997.

7 UNICEF. The health of the world's children. New York: UNICEF, 2003.
8 Davey Smith G, Dorling D, Mitchel R, et al. Health inequalities in Britain: continuing increases up to the end of the 20th century. J Epidemiol Community Health 2002;56:434-5.

9 Fiscella K, Franks P. Poverty or income in equality a predictor of mortality: a longitudinal cohort study. BMJ 1997;314:1724.

10 Gravelle $\mathbf{H}$. How much of the relation between population mortality and unequal distribution is statistical artefact? BMJ 1998;316:382.

11 Wolfson M, Kaplan G, Lynch J, et al. Relation between income inequality and morality: empirical demonstration. BMJ 1999;319:953-5.

12 Lynch JW, Davey-Smith G, Kaplan GA, et al. Income inequality and mortality: importance to health of individual income, psychosocial environment, or material conditions. BMJ 2000;320:1200-4.

13 Dummer TJB, Dickinson HO, Pearce MS, et al. Stillbirth risk with social class and deprivation: no evidence for increasing inequality. J Clin Epidemiol 2000;53: 147-55.

14 Parker L, Smith J, Dickinson H, et al. The creation of a database of workers at a nuclear facility: an exercise in record linkage. Appl Occup Environ Hyg 1997; 12:40-5.

15 Townsend P, Phillimore P, Beattie A. Health and deprivation: inequality and the North. London: Routledge, 1988.

16 Environmental Systems Research Institute. Arc/Info version 7.0.3. California: Environmental Systems Research Institute, 1995.

17 Wagstaff A, Paci P, Van Doorslaer. On the measurement of inequalities in health. Soc Sci Med 1991;33:545-57.

18 Royall M. Model robust confidence intervals using maximum likelihood estimators. International Statistical Review 1986;54:221-6.

19 StataCorp. STATA Statistical Software: release 6.0. College Station. TX: Stata Corporation, 1999.

20 Dolan SA, Jarman B, Bajekal M, et al. Measuring disadvantage: changes in the underprivileged area, Townsend, and Carstairs scores 1981-91. J Epidemiol Community Health 1995;49:S30-3.

21 Hosmer DW, Lemeshow S. Applied logistic regression. New York: Wiley, 1989.

22 Arntzen A, Moum T, Magnus P, et al. Marital status as a risk factor for fetal and infant mortality. Scand J Soc Med 1996;24:36-42.

23 Marsh A, McKay S. Poor smokers. London: Policy Studies Institute, 1996.

24 Macfarlane A, Mugford M. Birth counts: statistics of pregnancy and childhood, volumes 1 and 2. London: Stationery Office, 2000.

25 Pharoah POD. Perspectives and patterns. Br Med Bull 1986:42:119-26.

26 Macfarlane A. The downs and ups of infant mortality. BMJ 1988;296:230-1.

27 Alberman E, Botting B, Blatchly N, et al. A new hierarchical classification of causes of infant deaths in England and Wales. Arch Dis Child 1994:70:403-9.

28 Botting B, Crawley R. Trends and patterns in childhood mortality and morbidity. In: Botting B, eds. The health of our children: decennial supplement. London: HMSO, 1995.

29 Pamuk ER. Social class inequality in infant mortality in England and Wales from 1921 to 1980. European Journal of Population 1988;4:1-21.

30 Morris JN, Blane DB, White IR. Levels of mortality, education, and social conditions in the 107 local education authority areas of England. J Epidemiol Community Health 1996;50:15-17.

31 Martuzzi M, Grundy C, Elliott P. Perinatal mortality in an English health region: geographical distribution and association with socio-economic factors. Paediatr Perinat Epidemiol 1998;12:263-76.

32 Whitehead M, Drever F. Narrowing social inequalities in health? Analysis of trends in mortality among babies of lone mothers. BMJ 1999;318:908-12.

33 Curtis $\mathbf{S}$, Jones IR. Is there a place for geography in the analysis of health inequalities? Sociol Health III 1998;5:645-72.

34 Sloggett A, Joshi H. Higher mortality in deprived places: community or personal disadvantage. BMJ 1994;309:1470-4.

35 Jones K, Duncan C. Individuals and their ecologies: analysing the geography of chronic illness within a multilevel modelling framework. Health and Place 1995; 1:27-40.

36 Fieldhouse EA, Tye R. Deprived people or deprived places? Exploring the ecological fallacy in studies of deprivation with the Sample of Anonymised Records. Environment and Planning A 1996;28:237-59.

37 Gatrell AC. Geographies of health. Oxford: Blackwell, 2002. 